\title{
Musical Characteristics and Language Skills of Chinese Musical Jinsha
}

\author{
Fangya Qiu \\ Sichuan Normal University \\ Chengdu, China
}

\begin{abstract}
With the improvement of the material culture of human beings, people start to seek spiritual enjoyments. The musical first prevailed in western European countries and was introduced to China in 1980s with the reform and opening-up policy and has played an important role in Chinese market since then. Of course, Chinese musical has gone through a long way from simulation to originality, and now we are able to create excellent original Chinese native musicals, such as Jinsha. The great achievements are due largely to the hardworking creative workers in musical field. To make greater breakthrough in Chinese musical, deep analysis and research on some successful musicals are necessary. In addition, awareness of one's own limitations leads to improvements so it is of great significant to study the musical characteristics and language skills, and to analyze the characters and singing styles of classic musicals. As one of the classic original native musicals, Jinsha has many classic passages that are used as main materials of musical and widely learnt in institutions of higher learning. The classic passages, singing style and language skills of Jinsha have been regarded as a model of musicals and are learnt, simulated and widely spread. Therefore, it is essential to study the classic passages and language skills.
\end{abstract}

Keywords-musical characteristics; language skills; singing style; character analysis

\section{INTRODUCTION}

With the advance of science and technology, people's living standards improve gradually as well. People are not satisfied by adequate food and clothes any more, and they start to seek spiritual enjoyments such as traveling, reading and listening to music. Lots of them begin to get access to musical to cultivate their tastes and to purify their souls so as to relax themselves physically and mentally. As a result, with the continuous improvement of our society, western musicals are constantly introduced to Chinese mainland and this give people a chance to have a comprehensive understanding of the musical. Now Chinese people start to appreciate the musicals from Europe and the America and also accept and support original Chinese musicals.

The most important assessment criterion of a wonderful musical is its music that is considered as the soul of the music. However, good music is far from adequate for a great musical because a musical is not equivalent to music, as a musical requires singing as well as excellent acting and expressive ability of a performer. A musical reveal the characters to the audience vividly by performers' singing, and only in this way, can the musical be expressed in perfect harmony, and can the audience obtain immersive experience. A successful performance has to be the one where performers manifest the personality characteristics of the musical's characters to attract audience. Meanwhile, the application of singing skills and enunciation of words during singing also makes contributions to the characterization. In addition, for a drama, language is the most crucial part, because it helps the playwright to portray the characters more vividly and more lively in the comparison between different characters to drive the narrative forward. Therefore, this paper mainly explores the musical characteristics and language skills of the classic passages in Jinsha by analyzing its characters and singing style, etc.

\section{The AdVEnt AND Prosperity OF THE MUSICAL}

A musical is a kind of comprehensive stage arts that merges various elements of art. Originated in and first developed in western countries, musical was introduced to China afterwards now takes a place in Chinese musical stage. Additionally, musical has profound historical foundations going through a long developing history, so it has a welldeveloped system in all aspects, no matter in its contents and themes or in its e movements. Its development process in China is the same as that in Western world. Musicals are popular with people on account of its lively presentation techniques and accessible language. The initial musicals are mostly comedies which blend pleasurable elements such as songs and dances together with vaudevilles and fascinate people all over the world. Musical rose with the performance of the musical Show Boat that was a hit at that time, leading to the pursuit of musicals in America and drawing the attention from other places of the world. Of course, the small success of Show Boat is not enough to appeal to the whole world, but a big surprise is in the air with the advent of other musicals. Finally, with the advent of the musical West Side Story, Americans start to accept musicals as a new kind of culture and musicals began to develop rapidly since. Later, as the communication deepens between western and eastern cultures under the influence of economic globalization, musicals start to be accepted and develop around the world.

With the development upsurge of western musicals, in the period of New Culture Movement, some of Chinese progressive intellectuals and arctic researchers start to 
explore musicals driven by curiosity to new culture and knowledge. Under their unremitting efforts, some musical works were created, which were considered as the origination of Chinese musical drama. These works were created according to the unique thinking and culture of children, which are representative. Although China was suffering war and in a difficult situation of internal disorder and foreign invasions at that time, it still has the ability to develop its own musicals. This has laid a solid foundation to the advent of Chinese musicals. With the change of Chinese political system and the communication of western and eastern cultures under constantly developing economic society, the first original Chinese musical Young People Today was finally appeared in 1980. Filling in the blank of Chinese musical history, the first musical is a significant breakthrough in Chinese musical. Musical quickly became popular with people and created a stir by means of its accessible language and abundant content with connotations. Afterwards, outstanding original Chinese musicals were produced one after another such as the Passion and the Love with refined language and refined style, the affecting one Papa, Can You Hear Me Sing and Love in the World. These wonderful works were sprouting up everywhere and declared that musical entered into Chinese market. Although original Chinese musical is inspired by western counterparts and starts relatively late, it develops rapidly. Since the musical creators did not have a deep understanding of musical at the first beginning, neither does its intension, they start with imitation then to originality and finally create wonderful original native works that are popular with people by gathering experience gropingly. In 2005, the advent of Jinsha created another upsurge of original Chinese musicals.

\section{BACKGROUND OF THE CREATION OF JINSHA}

In fact, Jinsha culture began to be heard by people in March, 2001 when the Jinsha Site was found in a construction site of Jinsha Village, Qingyang district, western Chengdu city, Sichuan province. The proposal of Jinsha culture is one of the resounding archaeological achievements all over the world. Thousands of valuable antiques were found in the site, such as exquisite jadewares, ivory, bronze wares and earthenwares. In addition, Jinsha culture was not noted in historical records and amazed the world as these historical relics were found. The ring for the divine sunbird is so gorgeous. Certainly, the discovery of Jinsha had drawn the attention from the world. With the great respect and love for Jinsha culture, the musical creator Ye Dan put forward an idea based on the actual situations after initiating many investigations and researches. That is, he wanted to create a musical which reveals the classic of Jinsha and mixes with modern elements and which he believed to be a world-astounding masterpiece. It is worthy to mention that the chief director and composer of the musical Jinsha is a famous Chinese musician. Because of the unremitting efforts of these creators, Jinsha filled with classical beauty and modern glamour was created successfully and made its debut in Beijing Poly Theatre on April 8, 2005. Since then, the musical Jinsha become one of the most famous representatives of original Chinese musicals and many songs in it have also been widely spread.

\section{The CREATIVE TeChNiQues AND CHARACTERISTICS OF THE VOCAL MUSIC IN JISHA}

Musical is an artistic form that blends song and dance, music and vaudeville, and it expresses the emotion mainly through characterization. Therefore, characters are the essence of a musical. A successful musical needs the performance of performers which endows a musical with a soul. The audience mainly obtains information according to facial expressions, languages, and body movements and gestures of performers with the help of scene music and dance, etc. to read the musical. Nowadays, with the advance of living standards of human beings, they have higher spiritual requirements. In addition, musicals are gradually improving now. Based on the structural composition of the world's most famous musical, a musical is mainly composed music score (rich with emotion to drive the narrative forward), lyrics and play (dialogues). Additionally, lyrics and play are also known as the combination of librettos which is often called in operas. Most of musicals last 2 to 3 hours, but the time range is not compulsory and has a floating zone. In general, an integrated musical along with the intermission is divided into two acts, containing 20 to 30 songs. The musical Jinsha are filled with historical and cultural elements, magnificent music and some modern songs. The music and songs echo each other to create an atmosphere of emotion and help to shape passionate characters.

\section{A. The Method of Lyric Music Echoing the Scene Music}

Jinsha is a musical that is mainly characterized by narrative and the creator hopes to drive the plot forward through unfolding the narrative smoothly, so some lyric music is added during the story-telling of the characters. The lyric music and scene music echoes each other and their combination helps the performer get into character more easily and perform more naturally and also makes the presentation of characters ' emotion more exquisite and vivid. Musical is a kind of blended artistic form that requires performers to perform well and harmoniously not only in dancing, singing, narrating, etc, but also all aspects. A musical has music pieces but not equal to pure narrative with words. This requires that a musical has to be the one where the internal world of characters can be expressed with the help of lyric music through band playing. In addition, the composed music in the musical is basically both powerful and lyric, which can draw the psychological distance between the audience and characters close, and make the audience identify with the characters and drive the plot forward naturally at the same time. When the narrative is near gentle, it is the time to shape characters. At this time, by combining lyric music and scene music as a foreshadowing, the emotions of characters are expected to be revealed incisively and vividly and echo the narrative content without off topic. For example, in the musical A Time For Us, in the scene where two lovers reunite after thousands of years' separation, but soon one of them has to face the death of the other. By rights, the arrangement of the scene and the scene music have already created a very mournful occasion, but in the ending, the creator still used lyric music to foil the tragedy where the two lovers still cannot to be together after thousands of years' waiting. The arrangement makes the 
audience feel sorry for the tragedy and sigh that "not every Jack has his Jill"'.

\section{B. Accessible Melody Mainly with Pop Songs}

As we all know, the most important feature of a musical is its accessibility with various subjects that means it is suitable for all people and for all ages. It's like writing an essay that every passage, every sentence and even very word is to serve the subject and every argument method utilized is to demonstrate the gist of the essay. Therefore, it's easy to understand that the reason why the music has to serve the musical is that the music is the aid which helps to shape characters with intact personality and rich emotions and to create an emotion atmosphere matching the scene. In this way, the audience is able to have a comprehensive understanding of the story the musical is telling and the feelings the musical wants to reveal and to find out the hidden intension of the musical with the help of the imagination. The musical Jinsha contains modern popular elements but keeps its classic artistry. In general, a musical with historical and cultural features is deemed to match with powerful and magnificent music to create a splendid atmosphere, although this kind of thought is limited but it accords with the practice to some degree. Nevertheless, facing historical musicals with historical cultural elements, some well-known composers are not affected or restrained by the mindset. For example, in Jinsha, they also combine the powerful music with modern pop songs to endow Jinsha with both classic and modern beauty, reaching a harmony of classic and popular styles. There are many pop songs in Jinsha, such as Miss You and At That Time, and the pop music makes the melody bright and accessible and easy to be accepted, conforming to modern people's tastes and the rapid developing society as well.

\section{ANALYSIS OF THE CHARACTERS AND LANGUAGE SKILLS OF JINSHA}

With profound historical and cultural background, Jinsha is a musical that has its own singing method and music for voices. Though Jinsha is different with other elegant artistic forms, classic beauty still can be found there, satisfying both refined and popular taste, and this kind of effect is attributed to the application of language skills. To close the gap between the audience and the character, the creators tried their best to simplify the contents and language. Obviously, a successful musical is closely related to the body movement, language and expressions, because it is the perfectly portrayed character that endow the musical a soul. Therefore, this requires creators of musicals to make full use of the language skills and wonderful performance of the performers such as the methods of overstatement, synaesthesia and metaphor, together with humorous language style to produce an outstanding musical.

\section{A. Voice Shaping of the Characters}

Stage voice mainly consists of pitch, timbre, the length and intensity of the sound. A musical are colorful because of its changing. Every performer is supposed to have a deep understanding of his or her own image and the personality of the character he or she portrayed according to the position of the character. Based on the comprehensive understanding, the performer can adjust the timbre, the length of sound, speed of speaking and expand the register, etc, to create a perfect character. It is easy to understand that if you want to play a teenage girl, you have to speak with the tone that is peculiar to a teenage girl, which is pure, sweet and filled with curiosity and yearning for the world, but not with the tone belonging to a woman or a shrew. The main characters in Jinsha include Jin, Sha, an ebony elf named Chou and Mrs. Flower. Thereinto, Jin is a pretty girl who is the incarnation of a reserved and beautiful sunbird. The actress mainly uses her natural voice with the aid of the falsetto voice, and head resonance is frequently applied while singing. Besides, the actress's voice is expected to be clear, sweet and soft in timbre with high pitch. Sha is a handsome young man with masculinity, who is responsible, ambitious energetic, and therefore, the voice is expected to be alto voice that is deep and strong and uttered mainly by mouth and a little by the chest, without the sense of powerlessness. Chou is a mischievous and cheerful young man with distinctive personality, and thus the performer shall use his natural voice based on alto voice. Mrs. Flower is elegant and shall be portrayed as confident and a little ostentatious on the basis of chest and oral resonance.

\section{B. The Integration of Body Movements and Facial Expressions of Performers Together with Language Skills and Background Music}

A musical is not just music but more than that it's artistic performing. Musical is actually translated as opera in the first beginning as it is similar to opera not only because it contains music but more in the expression method which requires performers to convey the theme of the musical using their body movements and gestures. For example, a musical needs dancers to express through dancing and moderate facial expressions as well. Thus, musical is an artistic performing form that resembles opera and the only difference between them is that the music, that is, the music in an opera is traditional operas and in a musical that is elegant music. Performers have to get acquainted with the script to grasp its essence so as to play their parts well, and in terms of this, musical is similar to television show and film which require outstanding acting and professional quality. For instance, in the musical Jinsha, when the two lovers reunite after thousands of years separation, the performs applied body language like crying with joy, locking eyes without words, etc. to perfectly present their unspeakable excitement. As a result, a successful musical requires good voice and excellent body movements to reach a perfect integration with facial expressions, language of the characters along with the background music.

\section{CONCLUSION}

The musical Jinsha is filled with historical and cultural elements, magnificent music and some modern pop songs, and the latter two echo each other to create an atmosphere with rich emotions. In addition, the method of lyric music echoing the scene music and the melody that most are pop 
music applied in the musical make the musical has its own unique artistic style. Besides, the singer of a musical has to learn to analyze the script and the characters in it, because singing is one of the methods of characterization. A musical is mainly characterized by telling stories and all the arias are closely related to the development of the narrative, so performers have to memorize the lyrics and grasp the language skills when singing as well so as to convey the emotions correctly to the audience and make them to resonate. As a result, it is especially important to have a good command of singing techniques and language skills.

\section{REFERENCES}

[1] Fang Qian. Analysis of the four elements of musical based on Jinsha. Writer Magazine, 2009 (14).

[2] Chen Dun. Literary Comprehension of the Musical Jinsha. Consume Guide, 2008 (2).

[3] Chen Weiping. Science and Technology: Leading the Fashion Trend of Stage Based on Jinsha. Sichuan Drama, 2008 (1).

[4] Zhao Zhiqi. Investigation of the Acceptance System Construction in the Perspective of Sociology of Music. Journal of Sichuan College of Education, 2008, 24 (12).

[5] Li Qian, Li Li. Diversity of Performance Art of Vocal Music Based on Multi-Symphonies.2008.

[6] Wang Yanheng. Modern Chinese Folk Music in the Perspective of American Musical. Beauty and Times, 2005.

[7] Cai Dongmin. China Needs Its Own Script Doctor. Playwright, 2009 (1).

[8] Zhang Weigang. The Reason for Success of Broadway Musical in China. Mountain Flower, 2008 (11).

[9] Yang Jia. Rise of the British Musical in Broadway. Music Education in China, July 2008: 43-45.

[10] Zhang $\mathrm{Xu}$, Wen Shuo. Introduction of Musical [M].Shanghai, Shanghai Music Publishing House, September 2004.

[11] Lu Guangrui. Appreciation of Chinese and Foreign Opera, Dance Drama and Musical. Chongqing, Southwest China Normal University Press, January 2008.

[12] Tang Xiaoning, Yang Jing. Art of Musical and Practice [M]. Wuhan, Wuhan University of Technology Press, December 2004.

[13] Stephan Pflicht (author), Yang Zuqun (translator). The Musical Guide. Changsha, Hunan literary press, January 2008.

[14] Xiu Liting. Primary Investigation of Body Shaping of Musical Performers. Shandong College of Arts, 2007.

[15] Niu Guiji. Analysis of the Development Prospect of Musical. Art and Technology, February 2004

[16] Cui Xiaolan. Opera in Chinese Modern Music. Hundred Schools in Arts, 2007 (8).

[17] Zheng Hui, Localization of Chinese Musical. Musicology in China (quarterly), 2006(3)

[18] Wang Min. Brief Introduction of the Development History of Broadway Musical. Qilu Realm of Arts, 2004 (3).

[19] Liu Hongmei. Analysis of Musical Performer Training, Art Education, 2008 (5).

[20] Liu Hongmei. Primary Investigation of Character Creation of Musical Art Theory, 2008.

[21] Yu Yizi. Singing Style and Voice Concept of the Singing Technique of Musical. Journal of Wuhan Conservatory of Music, 2007 (4).

[22] Guo Yu. Singing Technique and the Expressive Effect. Hunan Normal University, May 2007.

[23] Liu Hongmei. Application of Stage Action Rules in the Performance of Musical. Art Review, 2008(9).
[24] Wang Yana. Review of the First Seminar about Teaching and Creation of Musical. Drama, Journal of Central Academy of Drama, 2008 (1)

[25] Cheng Dan. Primary Investigation of the Diversity of the Singing Style of Musical. Journal of Xinghai Conservatory of Music, June 2005 (2).

[26] Peng Yuandi. Difference and Developing Trend of Chinese and American Music. Chinese Music (quarterly), 2008 (2).

[27] Zhang Dongmei. Musical Style Combining Elements of Classic Music and Bel Canto. South North Bridge, November 2008.

[28] Zhao Ting. Phantom of the Opera Capital Normal University. Capital Normal University, April 2008. 